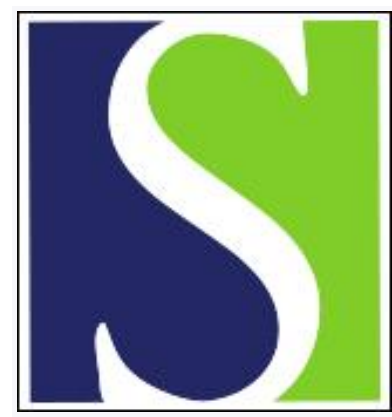

Scand J Work Environ Health 2018;44(5):485-495

https://doi.org/10.5271/sjweh.3736

Published online: 02 May 2018, Issue date: 01 Sep 2018

Clustering of job strain, effort-reward imbalance, and organizational injustice and the risk of work disability: a cohort study

by Juvani A, Oksanen T, Virtanen M, Salo P, Pentti J, Kivimäki M, Vahtera J

No previous study has examined multiple workplace stressors in relation to disability pension. This study examined the associations of multiple work-related stressors with disability pensioning using self-reports and work-unit aggregates of job strain, effort-reward imbalance (ERI) and organizational injustice. The combination of job strain and ERI is associated with doubling the risk of disability pension due to depression.

Affiliation: Joint Authority of Karkkila and Vihti for Public Health and Social Services, Occupational Health Care Unit of Nummela, Nummenselkä 2, 03100 Nummela, Finland. anne.juvani@fimnet.fi

Refers to the following texts of the Journal: 2014;40(3):266-277 2016;42(5):395-404

The following article refers to this text: 2020;46(2):198-208

Key terms: cohort study; early exit; early retirement; effort-reward imbalance; ERI; job strain; mental health; occupational health practice; organizational injustice; work disability; work stress; work stressor

This article in PubMed: www.ncbi.nlm.nih.gov/pubmed/29777612 


\title{
Clustering of job strain, effort-reward imbalance, and organizational injustice and the risk of work disability: a cohort study
}

\author{
by Anne Juvani, MD, 1,2 Tuula Oksanen, MD, PhD, ${ }^{3}$ Marianna Virtanen, PhD, 3,4 Paula Salo, PhD, 3, 5 Jaana Pentti, BSc, ${ }^{2,3}$ \\ Mika Kivimäki, MD, PhD, 3,6,7 Jussi Vahtera, MD, PhD²
}

\begin{abstract}
Juvani A, Oksanen T, Virtanen M, Salo P, Pentti J, Kivimäki M, Vahtera J. Clustering of job strain, effort-reward imbalance, and organizational injustice and the risk of work disability: A cohort study. Scand J Work Environ Health. 2018:44(5):485-495. doi:10.5271/sjweh.3736
\end{abstract}

Objectives The aim of this study was to examine the association between co-occurring work stressors and risk of disability pension.

Methods The work stressors job strain, effort-reward imbalance (ERI), and organizational injustice were measured by a survey in 2008 of 41862 employees linked to national records of all-cause and cause-specific disability pensions until 2011. Co-occurring work stressors were examined as risk factors of work disability using Cox regression marginal models.

Results Work stressors were clustered: $50.8 \%$ had no work stressors [observed-to-expected ratio $(\mathrm{O} / \mathrm{E})=1.2$ ], $27.4 \%$ were exposed to one stressor $(\mathrm{O} / \mathrm{E}=0.61-0.81), 17.7 \%$ to two stressors $(\mathrm{O} / \mathrm{E}=0.91-1.73)$ and $6.4 \%$ to all three stressors $(\mathrm{O} / \mathrm{E}=2.59)$. During a mean follow-up of 3.1 years, 976 disability pensions were granted. Compared to employees with no work stressors, those with (i) co-occurring strain and ERI or (ii) strain, ERI and injustice had a 1.9-2.1-fold [95\% confidence interval (CI) 1.7-2.6] increased risk of disability retirement. The corresponding hazard ratios were 1.2 and $1.5(95 \%$ CI 1.0-1.8) for strain and ERI alone. Risk of disability pension from depressive disorders was 4.4-4.7-fold (95\% CI 2.4-8.0) for combinations of strain+ERI and strain+ERI+injustice, and 1.9-2.5-fold (95\% CI 1.1-4.0) for strain and ERI alone. For musculoskeletal disorders, disability risk was 1.6-1.9-fold (95\% CI 1.3-2.3) for strain+ERI and ERI+injustice combinations, and 1.3-fold (95\% CI 1.0-1.7) for strain alone. Supplementary analyses with work stressors determined using work-unit aggregates supported these findings.

Conclusions Work stressors tend to cluster in the same individuals. The highest risk of disability pension was observed among those with work stressor combinations strain+ERI or strain+ERI+injustice, rather than for those with single stressors.

Key terms early exit; early retirement; ERI; mental health; occupational health practice; work stress; work stressor.

Adverse psychosocial work stressors, such as job strain (1), effort-reward imbalance (ERI) (2), and organizational injustice (3) have been linked to impaired employee health and an increased risk of chronic diseases (4-9). These partially overlapping stressors capture various psychosocial characteristics of the work, workplace, and workers' perceptions. Job strain refers to a combination of high job demands and low job con- trol (1) whereas ERI concerns the possible imbalance between efforts an employee makes at work and the rewards (eg, salary, promotion prospects, esteem or job security) s/he gains (2). Organizational injustice, in turn, refers to a situation in which an employee perceives the organization's decision-making processes to be unfair and/or feels to be mistreated by his/her supervisor (3). Distributive justice, a further dimension of organiza-

1 Joint Authority of Karkkila and Vihti for Public Health and Social Services, Occupational Health Care Unit of Nummela, Vihti, Finland.

2 Department of Public health, University of Turku and Turku University Hospital, Turku, Finland.

3 Finnish Institute of Occupational Health, Helsinki, Finland.

4 Department of Public Health and Caring Sciences, Uppsala University, Sweden.

5 Department of Psychology, University of Turku, Turku, Finland.

6 Department of Epidemiology and Public Health, University College London, London, UK.

7 Clinicum, Faculty of Medicine, University of Helsinki, Helsinki, Finland.

Correspondence to: Anne Juvani, Joint Authority of Karkkila and Vihti for Public Health and Social Services, Occupational Health Care Unit of Nummela, Nummenselkä 2, 03100 Nummela, Finland. [E-mail: anne.juvani@fimnet.fi] 
tional justice not considered in this study, evaluates the fairness of exchange.

Recent meta-analyses on observational cohort studies have shown that all three stressors - job strain, ERI and organizational injustice - are associated with an increased risk of depressive disorders $(4,8)$, ischemic heart diseases (5), diabetes (9) and musculoskeletal diseases $(6,7)$. Previous studies have also shown a relationship between high levels of job strain, ERI and organizational injustice and an increased risk of all-cause disability pension (10-15), and disability pension due to depressive or musculoskeletal disorders $(10,11,14)$. A limitation in previous studies is that the focus has almost exclusively been on single stressors, although the health effects may vary between specific stressors and co-occurring stressors. Multiple stressors (ie, repeated hits from various stressors) may potentially be associated with more harmful effects on employee health and work ability than single stressors $(16,17)$, which may be more easily adapted. Supporting this reasoning, a recent multi-cohort study found that the combination of job strain and ERI was associated with a $40 \%$ higher risk of coronary heart disease while the excess risk for these stressors separately was only $16 \%$, compared to those with no work stressors (18). Few longitudinal studies have examined whether the three work stressors cluster (ie, occur together more often than expected by chance) and whether the effect of co-occurring work stressors on disability retirement is different from single work stressors. Furthermore, it is not known if a specific combination of these stressors is particularly harmful for work ability. Information on these issues has potentially important implications for prevention of early labor market exit.

We have previously studied job strain, ERI, and organizational injustice separately in association with all-cause and diagnosis-specific disability pension in the Finnish Public Sector (FPS) study $(10,11,14)$. In the present prospective study from the same cohort, we used updated data to examine the extent to which these three major work stressors cluster and whether specific combinations of co-occurring work stressors are particularly strongly related to the risk of disability pension due to any cause and disability from depressive or musculoskeletal disorders, the two most common causes of disability retirement $(19,20)$. In addition to work stressors measured by individual survey responses, we used work-unit aggregates of work stressors, assigned to every member of the work-unit eligible to the survey, as a more objective measure of the exposure to reduce reporting bias $(10,21)$.

\section{Methods}

The present study utilized the FPS study cohort, which includes all employees who have worked full-time (or full- or part-time in hospital districts) for $\geq 6$ months in the participating organizations (ten towns and six hospital districts). The Ethics Committee of the Hospital District of Helsinki and Uusimaa has approved the FPS study. The eligible population for this study comprised those employees who had a work contract for $\geq 6$ months in one of the target organizations in $2008(\mathrm{~N}=74$ 564) (figure 1). Of this eligible population, 52891 had responded to the 2008 FPS study survey (response rate $71 \%$ ) including questions on job strain, ERI, and organizational injustice. These survey responses were used to calculate a work-unit-based aggregate score of work stressors for each eligible study participant (either respondent or non-respondent). Of the 74564 eligible participants, we excluded those working in work units with $<3$ respondents $(\mathrm{N}=2212)$. Of the remaining employees, 65548 had earlier been linked to national health registers. Of these, we excluded those who had died or retired $(\mathrm{N}=1302)$ or were on a long ( $>90$ days) sick leave $(\mathrm{N}=719)$ at the beginning of the follow-up, which was the date of survey response in 2008. Thus, the final study sample comprised 63527 eligible employees and 45793 survey respondents. Finally, of the survey respondents, we excluded those with missing values on job strain, ERI or organizational injustice $(\mathrm{N}=1272)$ or any baseline covariate $(\mathrm{N}=2659)$. Thus, the final sample of survey respondents comprised 41862 employees.

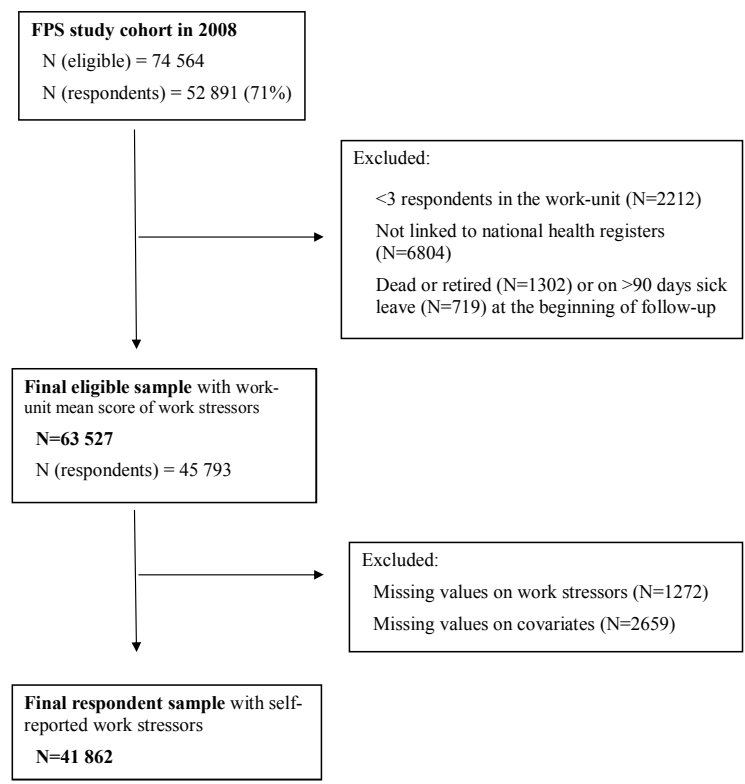

Figure 1. Flow chart of the study samples. [FPS=Finnish Public Sector] 


\section{Work stressors}

Exposure to job strain, ERI, and organizational injustice was measured from surveys similarly as in our previous studies $(10,11,14)$. Briefly, job demands and control were measured with 12 items derived from the Job Content Questionnaire (1). The mean of job control scores (9 items) was subtracted from the mean of demand scores (3 items) to measure the job strain score $(22,23)$. As earlier, we used a 4-item scale measuring efforts with one question and rewards with three questions as a proxy for ERI $(10,24)$. The remainder from the ratio of efforts and rewards (ie, effort score/ mean of reward scores) was used as an ERI score. The 4-item proxy scale has a relatively high correlation $(\mathrm{R}=0.6)$ with the 10 -item version of the standard ERI scale (10). The procedural and relational justice were measured with the original 13-item scale (25), and the organizational justice score was calculated as the mean of procedural and relational justice [ie, (mean of 7-item procedural justice + mean of 6-item relational justice)/2] (26). There was no substantial overlap between the stressors (all correlation coefficients $<0.30$ ). The highest quartile of job strain and ERI and lowest quartile of organizational justice indicated exposure to each psychosocial stressor, while the remaining three quartiles of each stressor were set as non-exposed. An 8-category variable was created to measure all the possible combinations of the three psychosocial stressors: (i) non-exposed, (ii) strain only, (iii) ERI only, (iv) injustice only, (v) strain+ERI, (vi) strain+injustice, (vii) ERI+injustice, and (viii) strain+ERI+injustice. Categories were exclusive, thus each participant belonged to one category only.

In addition to self-reported exposure, we calculated work-unit aggregates, as in our previous studies, to measure work stressors more objectively (ie, independently from individual characteristics) $(10,11,14,21)$. A work-unit aggregate was calculated for each psychosocial stressor as a mean value of all responses within the same work unit for work units with $\geq 3$ respondents and assigned for each participant in that work unit. The correlation coefficients of aggregated stressors varied between $0.11-0.32$. Similarly as for the self-reported exposure, the most unfavorable quartile was chosen as the exposure. The intra-class correlation for aggregated job strain was $16 \%, 4 \%$ for aggregated ERI, and $18 \%$ for aggregated organizational injustice, suggesting significant variance in job strain and organizational injustice between work units, and low within work-unit resemblance of individual answers to ERI.

\section{Disability pension}

We obtained information from the national pension records held by the Finnish Centre for Pensions. These nation-wide pension data were available for all participants regardless of their employment status or workplace at the follow-up. The starting dates and main diagnoses according to International Classification of Diseases, $10^{\text {th }}$ Revision (ICD-10) were retrieved on all full-time or partial disability pensions (permanent or fixed-term). All-cause disability pension and disability pension due to the two most common causes of disability retirement - depressive disorders (ICD-10 codes F32-F34) and musculoskeletal disorders (ICD-10 codes M00-M99) - were chosen as study outcomes $(10,11,14,19,20)$. The data were obtained for disability pensions granted after the start of the follow-up until 31 December 2011.

\section{Covariates}

Sociodemographic factors were derived from the employers' registers and included age, sex, the geographical location of the workplace (Northern, Southern or Central Finland) and occupational status. Occupational status was categorized according to the classification of occupations by the Statistics Finland (27) into higher non-manual, lower non-manual and manual. The level of education (primary, secondary or tertiary) was obtained from the records of Statistics Finland.

A history of physical illnesses (yes/no) and/or mental disorders (yes/no) was determined using data from various national registers. History of physical illnesses was coded "yes" if any of the following criteria was met: entitlement, effective at the beginning of the follow-up, to special reimbursement for the costs of medication for diabetes, asthma, chronic obstructive pulmonary disease, hypertension, cardiac insufficiency, or coronary heart disease; a record of cancer diagnosis; or purchases equal to $\geq 100$ defined daily dosages (DDD) of prescribed pain killers during the five years preceding the beginning of the follow-up. History of mental disorder was coded "yes" if any of these conditions was fulfilled: entitlement (effective at the beginning of the follow-up) to special reimbursement of antipsychotic medication; long-term sickness absence ( $>90$ days) or hospitalization due to mental disorders (ICD-codes F00-F99), reimbursed psychotherapy, and purchases ( $\geq 100$ DDD) of prescribed antidepressant medication during the five years before the beginning of the follow-up. Eligibility to special reimbursement for the costs of medication is granted by application (ie, statement from a physician) to all patients diagnosed with diabetes (type 1 or 2), cardiac insufficiency, asthma, coronary heart disease or psychotic disorders (such as schizophrenia, psychotic depression or bipolar depression). However, concerning chronic obstructive pulmonary disease and hypertension, the eligibility for the special reimbursement is stricter than indications to use medication for these diseases (28).

Behavior-related risk factors were derived from 
the baseline survey requesting information on smoking status (current smoker/ non-smoker), high alcohol intake (yes/no), obesity (yes/no), and sedentary lifestyle (yes/no). Alcohol abuse was coded "yes", if average absolute alcohol consumption was $\geq 210 \mathrm{~g}$ per week. If self-reports of height and weight resulted in body mass index (BMI) of $\geq 30 \mathrm{~kg} / \mathrm{m}^{2}$, the participant was coded as obese. Leisure-time physical activity $<2.0$ metabolic equivalent task (MET) hours per day (corresponding to approximately 30 minutes of walking) meant that participant had a sedentary lifestyle (29).

\section{Statistical analysis}

We used two samples: the survey respondents and eligible employees. For the survey respondents, we first calculated the rate of disability pension / 1000 person years by their baseline characteristics. For both samples, we studied the extent to which work stressors were clustered. The observed prevalence of each risk factor was the percentage of the sample reporting that risk factor. Expected prevalence for each combination of work stressors, assuming no association between the stressors (ie, independence), was calculated by multiplying the observed prevalence of each stressor (30). A measure of clustering was calculated as observed divided by expected $(\mathrm{O} / \mathrm{E})$ prevalence for each work stressor combination. Confidence intervals (CI) were obtained through bootstrapping procedures. Clustering was determined to have occurred when the $95 \% \mathrm{CI}$ for the $\mathrm{O} / \mathrm{E}$ did not include one (30).

Cox proportional hazard marginal models were used to examine the association between the combined variables of work stressors and disability pensioning. To take into account the nested structure of the data, workplace was used as the cluster variable. Because disability pensions are relatively rare and aggregated stressors were based on work units, we used employer (town, hospital district) as a cluster variable $(\mathrm{N}=16)$. Those with no work stressors acted as a reference group. The follow-up began from the date of survey response in 2008 and ended (i) if the participant was granted disability pension (study end-point) or old age pension, (ii) if $\mathrm{s} /$ he died, or (iii) on 31 December 2011, whichever came first. The models for the survey respondents were first adjusted for age, sex and region (geographical location of workplace) (model 1), then additionally also for occupational status, education, baseline physical and mental health, and behavior-related risk factors (obesity, smoking and high alcohol consumption) (model 2). Model 1 for the eligible population with work-unit aggregated exposure was similar to that of the survey respondents, model 2 was additionally adjusted for education and baseline physical and mental health. The cumulative incidence of disability pension due to any cause and depressive and musculoskeletal disorders by each category of self-reported exposure from age 30-63 years (the most common statutory retirement age) was studied with Kaplan-Meier estimator. All results were expressed as hazard ratios (HR) and their 95\% CI. The SAS statistical software version 9.4 (SAS Institute Inc, Cary, NC, USA) was used in all analyses.

\section{Results}

Most ( $80 \%)$ of the participants were women and worked in Southern Finland (56\%) (table 1). Over half of the study population had tertiary education $(60 \%)$ and half of them were in lower non-manual jobs $(51 \%)$. The highest rates of disability pension were observed for those who (i) were aged 50-60 years, (ii) were employed

Table 1. Participant characteristics and the rate of disability pension.

\begin{tabular}{|c|c|c|c|c|}
\hline Characteristic & Participants & $\%$ & $\begin{array}{l}\text { Rate / } 1000 \\
\text { person years }\end{array}$ & P-value \\
\hline All participants & 41862 & 100 & 7.5 & \\
\hline Sex & & & & $<0.0001$ \\
\hline Female & 33510 & 80.0 & 6.2 & \\
\hline Male & 8352 & 20.0 & 7.8 & \\
\hline Age (years) & & & & $<0.0001$ \\
\hline$<40$ & 10280 & 24.6 & 1.1 & \\
\hline $40-<50$ & 13376 & 32.0 & 3.0 & \\
\hline $50-<60$ & 14479 & 34.6 & 15.6 & \\
\hline$\geq 60$ & 3727 & 8.9 & 11.3 & \\
\hline Location of workplace & & & & $<0.0001$ \\
\hline Southern Finland & 23235 & 55.5 & 6.6 & \\
\hline Central Finland & 14885 & 35.6 & 7.8 & \\
\hline Northern Finland & 3742 & 8.9 & 11.4 & \\
\hline Occupational status & & & & $<0.0001$ \\
\hline Upper non-manual & 14640 & 35.0 & 3.5 & \\
\hline Lower non-manual & 21406 & 51.1 & 7.7 & \\
\hline Manual & 5816 & 13.9 & 16.6 & \\
\hline Education & & & & $<0.0001$ \\
\hline Tertiary & 25143 & 60.0 & 4.4 & \\
\hline Secondary & 13959 & 33.4 & 10.9 & \\
\hline Primary & 2760 & 6.6 & 19.6 & \\
\hline Physical illness & & & & $<0.0001$ \\
\hline No & 28540 & 68.2 & 3.8 & \\
\hline Yes & 13322 & 31.8 & 15.4 & \\
\hline Mental disorder & & & & $<0.0001$ \\
\hline No & 37624 & 89.9 & 6.4 & \\
\hline Yes & 4238 & 10.1 & 16.8 & \\
\hline Smoking status & & & & $<0.0001$ \\
\hline Non-smoker & 35669 & 85.2 & 7.0 & \\
\hline Smoker & 6193 & 14.8 & 10.2 & \\
\hline High alcohol & & & & 0.10 \\
\hline consumption & & & & \\
\hline No & 38332 & 91.6 & 7.3 & \\
\hline Yes & 3530 & 8.4 & 8.9 & \\
\hline $\begin{array}{l}\text { Obesity (body mass } \\
\text { index>30 kg/m²) }\end{array}$ & & & & $<0.0001$ \\
\hline No & 35274 & 84.3 & 6.6 & \\
\hline Yes & 6588 & 15.7 & 11.8 & \\
\hline $\begin{array}{l}\text { Leisure-time physical } \\
\text { inactivity }\end{array}$ & & & & $<0.0001$ \\
\hline No & 31611 & 75.5 & 6.1 & \\
\hline Yes & 10251 & 24.5 & 11.6 & \\
\hline
\end{tabular}


Table 2. Clustering of job strain, effort-reward imbalance (ERI) and injustice. Observed prevalence and observed/expected (O/E) prevalence ratio and their $95 \%$ confidence intervals ( $\mathrm{Cl}$ ) for all combinations of the stressors. [+ = presence of risk factor; - = absence of risk factor].

\begin{tabular}{|c|c|c|c|c|c|c|c|c|c|}
\hline \multirow{2}{*}{$\begin{array}{l}\text { Stressors } \\
\text { (N) }\end{array}$} & \multicolumn{3}{|c|}{ Work stressor a } & \multicolumn{3}{|c|}{ Eligible population ( $\mathrm{N}=63527$ ) } & \multicolumn{3}{|c|}{ Respondents ( $N=41862)$} \\
\hline & Strain & ERI & Injustice & Observed & O/E & $95 \% \mathrm{Cl}$ & Observed & O/E & $95 \% \mathrm{Cl}$ \\
\hline 0 & - & - & - & 50.8 & 1.21 & $1.20-1.21$ & 51.1 & 1.24 & $1.23-1.25$ \\
\hline 1 & + & - & - & 8.6 & 0.61 & $0.60-0.62$ & 9.0 & 0.64 & $0.63-0.66$ \\
\hline 1 & - & + & - & 7.5 & 0.53 & $0.52-0.54$ & 9.3 & 0.62 & $0.61-0.64$ \\
\hline 1 & - & - & + & 11.3 & 0.81 & $0.80-0.82$ & 9.4 & 0.69 & $0.68-0.71$ \\
\hline 2 & + & + & - & 8.1 & 1.73 & $1.70-1.77$ & 6.0 & 1.18 & $1.14-1.21$ \\
\hline 2 & + & - & + & 4.3 & 0.91 & $0.88-0.93$ & 4.0 & 0.87 & $0.83-0.90$ \\
\hline 2 & - & + & + & 5.3 & 1.14 & $1.11-1.17$ & 4.9 & 1.00 & $0.97-1.04$ \\
\hline 3 & + & + & + & 4.1 & 2.59 & $2.51-2.68$ & 6.4 & 3.85 & $3.73-3.97$ \\
\hline
\end{tabular}

${ }^{a}$ Mean cut-off values were -0.168 for aggregated (eligible population) job strain, 1.615 for ERI and 3.159 for injustice, while mean cut-off values for self-reported (respondents) job strain, ERI and injustice were $0.222,1.666$ and 2.920, respectively.
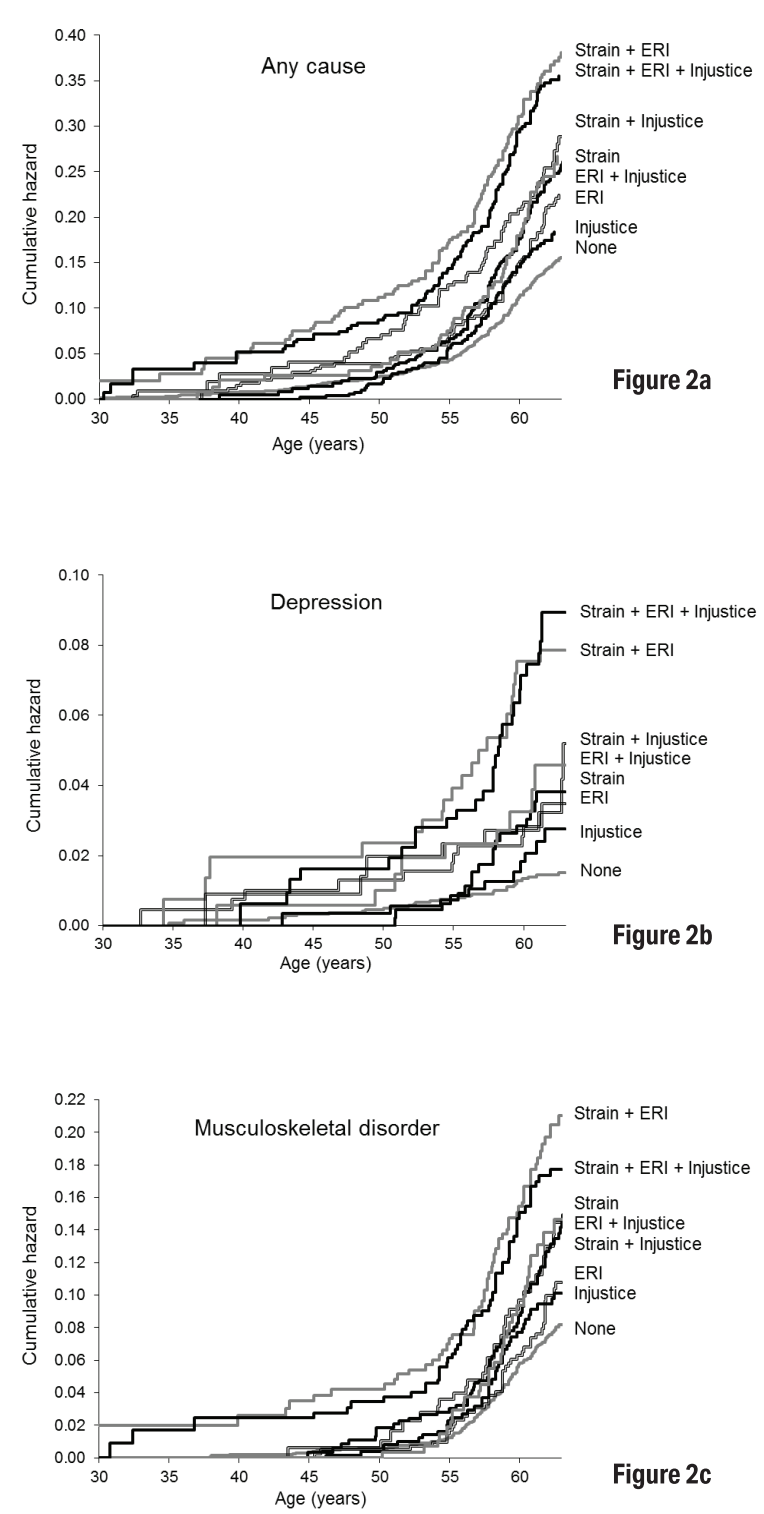

Figure 2. Cumulative hazard curves of all-cause and diagnosis specific disability pension by combinations of self-reported workstressors. [ERI=effortreward imbalance.] in manual jobs, (iii) had primary education only and (iv) had physical or mental illnesses.

Half of the participants were not exposed to any of the work stressors, about a quarter were exposed to 1 stressor, one fifth to a combination of any 2 stressors and around $5 \%$ to all 3 stressors (table 2). The 3 stressors were clustered so that the observed prevalence of having 0 or 2-3 stressors was significantly higher than expected, and the observed prevalence of having only 1 stressor was significantly lower than expected. The highest $\mathrm{O} / \mathrm{E}$ ratio was observed for having all 3 work stressors both in the eligible population and among the survey respondents [O/E 2.6 (95\% CI 2.5-2.7) and 3.9 (95\% CI 3.7-4.0), respectively].

During a mean 3.1 years of follow-up, altogether $1678(2.6 \%)$ eligible participants and $976(2.3 \%)$ survey respondents were granted a disability pension. Figure 2 shows the cumulative hazard curves of disability pension by categories of self-reported work stressors for ages 30-63 years. The dispersion of hazard curves of all-cause disability pension was observed from the 45 years of age onward (figure $2 \mathrm{a}$ ). By the age of 63 years, $15 \%$ of the employees who were not exposed to any of the stressors had ended up on disability pension. Among those exposed to both job strain and ERI, one fifth of the employees had retired due to a disability by the age of 57 years, while - by the age of 63 - this proportion was almost $40 \%$. The cumulative hazard curves of disability pension due to depressive disorders are illustrated in figure $2 \mathrm{~b}$ and those of disability pension due to musculoskeletal disorders in figure $2 \mathrm{c}$.

\section{Clusters of self-reported work stressors and disability pension}

Table 3 shows the risk of disability pension for different combinations of self-reported strain+ERI+injustice compared to the non-exposed. Adjusted for demographics and region, the risk of all-cause disability pension was elevated for all stressor categories. The 
highest risk was observed for the clusters of work stressors, especially the combination of strain+ERI and strain+ERI+injustice [HR 2.8 (95\% CI 2.3-3.4) and 2.5 (2.2-2.9), respectively]. Further adjustment for education, occupational status, baseline physical and mental health and health behavior-related risk factors attenuated the observed associations by $39-52 \%$. The risks for the clusters of work stressors remained above that of single stressors and were highest for the strain+ERI and strain+ERI+injustice combinations [HR 2.1 (95\% CI 1.8-2.6) and 1.9 (1.7-2.2), respectively]. For strain, ERI and injustice only, the corresponding HR were 1.5 (95\% CI 1.2-1.8), 1.2 (95\% CI $1.0-1.5)$ and 1.2 (95\% CI 0.9-1.4).

Table 3 also shows the risk of disability pension due to depressive disorders for the combinations of self-reported psychosocial stressors compared to the non-exposed. Adjusted for demographics and region, the HR varied between 2.0-2.7 (95\% CI 1.1-4.1) for the single stressors and between 3.0-6.5 (95\% CI 1.6-9.8) for their different combinations. These associations attenuated by $10-19 \%$ in the fully adjusted models. The highest risks were observed for the strain+ERI and strain+ERI+injustice combinations [HR $4.4(95 \% \mathrm{CI}$ 2.4-8.0) and 4.7 (95\% CI 2.9-7.7), respectively].

The last column of table 3 shows the associations between combinations of self-reported work stressors and risk of disability pension due to musculoskeletal disorders compared to the non-exposed. Adjusted for demographics and region, this risk was elevated for all stressor categories except organisational injustice alone.

Again, highest risk was observed for the clusters of work stressors, especially the combination of strain+ERI and strain+ERI+injustice [HR $2.6(95 \%$ CI 2.2-3.0) and 2.2 (1.7-2.7), respectively], while for the single stressors the HR varied between $1.3-1.7$ (95\% CI 1.0-2.1). These associations attenuated by $35-75 \%$ in the fully adjusted models and remained significant for strain only [HR 1.3 (95\% CI 1.0-1.7)], and the strain+ERI, ERI+injustice and strain+ERI+injustice combinations [HR $1.9(95 \% \mathrm{CI}$ 1.5-2.3), $1.6(1.2-2.3)$ and $1.6(1.3-2.0)$, respectively].

\section{Clusters of aggregated work stressors and disability pension}

Table 4 shows the risk of all-cause and cause-specific disability pension for the clusters of aggregated work stressors. In general, the results were in line with those obtained from self-reports, although with lower HR. Adjusted for demographics and region, all combinations of aggregated work stressors were associated with increased risk of all-cause disability pension while the stressors alone did not increase the risk. These risks attenuated by $35-46 \%$ after further adjustment for education and baseline mental and physical health and remained significant for the strain+ERI and strain+injustice combinations [HR 1.6 (95\% CI 1.3-1.9) and $1.2(1.0-1.4)$, respectively]. In relation to disability pension from depression, significant associations

Table 3. Combinations of self-reported work stressors and risk of disability pension ${ }^{\text {a }}$. Finnish Public Sector study respondents to 2008 survey ( $\mathrm{N}=41$ 862) were followed until the end of 2011. [Cl=confidence interval; ERI=effort-reward imbalance; HR=hazard ratio.]

\begin{tabular}{|c|c|c|c|c|c|c|c|c|}
\hline \multirow{3}{*}{$\begin{array}{l}\text { Measurement, } \\
\text { combination of stressors }\end{array}$} & \multirow{2}{*}{\multicolumn{2}{|c|}{ Participants }} & \multicolumn{6}{|c|}{ Cause of disability pension } \\
\hline & & & \multicolumn{2}{|c|}{ Any cause $(\mathrm{N}=976)$} & \multicolumn{2}{|c|}{ Depression $(\mathrm{N}=136)$} & \multicolumn{2}{|c|}{ Musculoskeletal $(\mathrm{N}=488)$} \\
\hline & $\mathrm{N}$ & $\%$ & HR & $95 \% \mathrm{Cl}$ & HR & $95 \% \mathrm{Cl}$ & HR & $95 \% \mathrm{Cl}$ \\
\hline \multicolumn{9}{|l|}{ Model $1^{b}$} \\
\hline None & 21379 & 51.1 & 1.00 & & 1.00 & & 1.00 & \\
\hline Strain only & 3768 & 9.0 & 1.73 & $1.43-2.11$ & 2.67 & $1.73-4.12$ & 1.68 & $1.33-2.13$ \\
\hline ERI only & 3875 & 9.3 & 1.45 & $1.19-1.78$ & 2.16 & $1.28-3.62$ & 1.28 & $1.05-1.57$ \\
\hline Injustice only & 3943 & 9.4 & 1.26 & $1.00-1.59$ & 1.97 & $1.11-3.51$ & 1.25 & $1.00-1.57$ \\
\hline Strain + ERI & 2492 & 6.0 & 2.78 & $2.30-3.35$ & 5.35 & $3.29-8.70$ & 2.57 & $2.18-3.02$ \\
\hline Strain + Injustice & 1674 & 4.0 & 1.93 & $1.49-2.50$ & 2.98 & $1.62-5.47$ & 1.71 & $1.27-2.29$ \\
\hline ERI + Injustice & 2051 & 4.9 & 1.83 & $1.38-2.42$ & 3.22 & $1.78-5.84$ & 1.94 & $1.44-2.61$ \\
\hline Strain + ERI + Injustice & 2680 & 6.4 & 2.53 & $2.24-2.86$ & 6.45 & $4.24-9.83$ & 2.17 & $1.73-2.72$ \\
\hline \multicolumn{9}{|l|}{ Model 2c } \\
\hline None & 21379 & 51.1 & 1.00 & & 1.00 & & 1.00 & \\
\hline Strain only & 3768 & 9.0 & 1.45 & $1.18-1.77$ & 2.47 & $1.52-4.01$ & 1.30 & $1.01-1.67$ \\
\hline ERI only & 3875 & 9.3 & 1.22 & $1.00-1.48$ & 1.87 & $1.11-3.17$ & 1.07 & $0.87-1.32$ \\
\hline Injustice only & 3943 & 9.4 & 1.16 & $0.94-1.43$ & 1.66 & $0.97-2.85$ & 1.19 & $0.96-1.48$ \\
\hline Strain + ERI & 2492 & 6.0 & 2.12 & $1.75-2.57$ & 4.40 & $2.43-7.96$ & 1.87 & $1.54-2.26$ \\
\hline Strain + Injustice & 1674 & 4.0 & 1.53 & $1.20-1.96$ & 2.30 & $1.23-4.31$ & 1.32 & $0.98-1.77$ \\
\hline ERI + Injustice & 2051 & 4.9 & 1.49 & $1.09-2.05$ & 2.38 & $1.30-4.34$ & 1.62 & $1.15-2.28$ \\
\hline Strain + ERI + Injustice & 2680 & 6.4 & 1.90 & $1.66-2.18$ & 4.70 & $2.86-7.70$ & 1.61 & $1.32-1.97$ \\
\hline
\end{tabular}


attenuated by $10-20 \%$ after full adjustments, showing a significantly increased risk for the ERI+injustice and strain+ERI+injustice combinations [HR $2.2(95 \% \mathrm{CI}$ 1.3-3.8) and 1.7 (1.1-2.7), respectively]. Regarding disability pension from musculoskeletal disorders, only the strain+ERI and ERI+injustice combinations adjusted for demographics and region associated with increased risk. After full adjustments, these associations attenuated by $52-59 \%$ and a significantly increased risk was observed for strain+ERI combination only [HR 1.5 (95\% CI 1.2-1.9)]. Only one significant association of any single stressor with the study end-points was observed (between strain and disability pension due to depression), but even this lost its significance once fully adjusted.

\section{Discussion}

This prospective cohort study of about 63000 Finnish public sector employees with information on aggregated and 42000 and self-reported job strain, ERI, and organisational injustice showed that these work stressors were clustered so that the observed prevalence of having no or several stressors was higher and having only one stressor lower than the expected prevalence. We found in the fully adjusted models that all combinations of self-reported and aggregated work stressors were associ- ated with increased risk of disability pension compared to those free of job strain, ERI and injustice. In addition, self-reported strain and ERI alone were associated with increased risk of disability pension, although the strength of these associations was less than half of that observed for the work stressor clusters. More specifically, the combinations strain+ERI and strain+injustice were associated with the risk of all-cause disability pension while - in relation to cause-specific disability pensions - ERI+injustice and strain+ERI+injustice increased the risk of disability due to depressive disorders and strain+ERI disability due to musculoskeletal disorders. Increasing the credibility of our findings, these observations were obtained both from a register follow-up of a large cohort of eligible employees using objective aggregated measures of work stressors as well as a nested survey cohort using self-reported work data. We are not aware of previous studies on the clustering of work stressors and the risk of all-cause and causespecific disability pension.

Most studies on work-related psychosocial factors are subject to subjectivity bias due to self-reported exposure measurements $(4,31)$ even though it has been argued that the effect of subjectivity on, for example, mean scores of ERI is not notable (32). Nevertheless, as, eg, sub-clinical depression may influence the reporting of working conditions and lead to disability pension during the follow-up, cohort studies that rely on self-reports of work stressors are open to reporting

Table 4. Combinations of aggregated work stressors and risk of disability pension a. Finnish Public Sector Study employees eligible to the 2008 survey ( $\mathrm{N}=63527$ ) were followed until the end of 2011. Work-unit aggregates are based on survey responses from 3540 work-units. [Cl=confidence interval; ERI=effort-reward imbalance; $\mathrm{HR}=$ hazard ratio.]

\begin{tabular}{|c|c|c|c|c|c|c|c|c|}
\hline \multirow{3}{*}{$\begin{array}{l}\text { Measurement, } \\
\text { combination of stressors }\end{array}$} & \multirow{2}{*}{\multicolumn{2}{|c|}{ Participants }} & \multicolumn{6}{|c|}{ Cause of disability pension } \\
\hline & & & \multicolumn{2}{|c|}{ Any cause $(\mathrm{N}=1678)$} & \multicolumn{2}{|c|}{ Depression (N= 241) } & \multicolumn{2}{|c|}{ Musculoskeletal $(\mathrm{N}=814)$} \\
\hline & $\mathrm{N}$ & $\%$ & HR & $95 \% \mathrm{Cl}$ & HR & $95 \% \mathrm{Cl}$ & HR & $95 \% \mathrm{Cl}$ \\
\hline \multicolumn{9}{|l|}{ Model 1 b } \\
\hline None & 32287 & 50.8 & 1.00 & & 1.00 & & 1.00 & \\
\hline Strain only & 5437 & 8.6 & 1.24 & $0.96-1.59$ & 1.38 & $1.04-1.83$ & 1.26 & $0.90-1.76$ \\
\hline ERI only & 4753 & 7.5 & 1.15 & $0.79-1.68$ & 1.26 & $0.89-1.78$ & 0.96 & $0.61-1.50$ \\
\hline Injustice only & 7208 & 11.4 & 0.96 & $0.81-1.14$ & 1.05 & $0.81-1.36$ & 0.78 & $0.55-1.11$ \\
\hline Strain + ERI & 5172 & 8.1 & 2.06 & $1.65-2.57$ & 1.45 & $1.02-2.06$ & 2.17 & $1.60-2.95$ \\
\hline Strain + Injustice & 2701 & 4.3 & 1.33 & $1.04-1.70$ & 1.14 & $0.88-1.48$ & 1.46 & $1.05-2.04$ \\
\hline ERI + Injustice & 3392 & 5.3 & 1.41 & $1.06-1.88$ & 2.40 & $1.35-4.27$ & 1.23 & $0.95-1.60$ \\
\hline Strain + ERI + Injustice & 2577 & 4.1 & 1.38 & $1.07-1.78$ & 1.78 & $1.09-2.92$ & 1.01 & $0.66-1.54$ \\
\hline \multicolumn{9}{|l|}{ Model $2^{c}$} \\
\hline None & 32287 & 50.8 & 1.00 & & 1.00 & & 1.00 & \\
\hline Strain only & 5437 & 8.6 & 1.09 & $0.88-1.35$ & 1.32 & $1.00-1.75$ & 1.05 & $0.77-1.43$ \\
\hline ERI only & 4753 & 7.5 & 1.01 & $0.71-1.45$ & 1.17 & $0.81-1.68$ & 0.83 & $0.56-1.24$ \\
\hline Injustice only & 7208 & 11.4 & 0.98 & $0.87-1.12$ & 1.02 & $0.79-1.31$ & 0.83 & $0.62-1.10$ \\
\hline Strain + ERI & 5172 & 8.1 & 1.57 & $1.28-1.92$ & 1.36 & $0.91-2.04$ & 1.49 & $1.15-1.93$ \\
\hline Strain + Injustice & 2701 & 4.3 & 1.19 & $1.01-1.41$ & 1.15 & $0.89-1.49$ & 1.22 & $0.97-1.53$ \\
\hline ERI + Injustice & 3392 & 5.3 & 1.27 & $0.94-1.71$ & 2.18 & $1.26-3.78$ & 1.11 & $0.84-1.47$ \\
\hline Strain + ERI + Injustice & 2577 & 4.1 & 1.28 & $0.98-1.66$ & 1.70 & $1.06-2.73$ & 0.92 & $0.59-1.43$ \\
\hline
\end{tabular}

a Analyzed with Cox proportional hazard marginal models, taking into account clustering of participants in workplaces.

${ }^{\mathrm{b}}$ Adjusted for age, sex and region (location of workplace).

${ }^{c}$ Additionally adjusted for education, and mental and physical health. 
bias. Moreover, individual differences, such as tendency to experience negative emotions, may have an impact on how employees perceive and report work stress (21, 31,33 ), and additionally affect their tendency to seek a disability pension. Reporting bias has been shown to inflate associations between job strain and the occurrence of depression (21). Use of work-unit-aggregated scores on the exposure is one way to control subjectivity and reporting biases $(10,11,14,21,33)$, a method also used in the present study. However, as true betweenindividual differences within the unit of aggregation are lost when assigning the mean score for all members of a work unit, associations between work-unit aggregated work stressors and work disability are more likely to represent under- than overestimates (33). The strongest evidence comes from converging findings based on self-reports and the more conservative aggregated measures. The agreement of results based on aggregated and self-reported measures of work stressors suggest that response bias is an unlikely explanation to our findings on the association between work stress and risk of disability pension from any cause or depressive disorders.

Previous studies have suggested that the health influences of job strain, ERI, and organizational injustice are complementary $(10,18,34-40)$. With few exceptions $(18,36,37,41,42)$, a critical weakness in the prior evidence is, however, the reliance on cross-sectional designs $(34,35,39,40,43)$ and the usage of only self-reported measures for both the exposure and the outcomes (34-36, 39, 41, 42). To the best of our knowledge, this is the only longitudinal study to examine clustering of work stressors and the risk of all-cause and cause-specific disability pension. Importantly, we were able to measure work stressors not only from self-reports but also independently based on work-unit aggregates (33). Moreover, the outcome was derived from reliable and accurate pension registers. Even though this study supports the suggestion that job strain and ERI are complementary $(10,18,34-40)$, the measures of work stress also partly overlap. Job strain is considered to concern task-level imbalance between "efforts" and "rewards", while ERI covers wider socioeconomic aspects, such as recognition and salary (44). ERI and organizational injustice (especially its distributive component, which was not included in present study) share similar conceptual background concerning the fairness of exchange. However, ERI is thought to operate on the individual level and in relation to rewards, while organizational injustice operates on the organizational level and in relation to other employees (36). Thus, an employee may find his/her efforts to be in balance with rewards but still find him/herself unequally treated when compared to other employees in the work unit.

We found that strain, ERI and organizational injustice are complementary to each other. The combination
strain+ERI had a major impact on the risk of disability pension due to any cause or musculoskeletal disorders but a minor impact on the risk of disability pension due to depressive disorders. ERI+injustice had a minor impact on the risk of disability pension due to any cause or musculoskeletal disorders but a major impact on the risk of disability pension due to depression. We have previously found in a sample drawn from earlier phases of the FPS study that job strain was associated with increased risk of disability pension due to musculoskeletal diseases (11) while ERI was associated with disability pension due to depressive disorders (10). These present results highlight the importance of considering the work stressors combinations to better understand the risks they pose to employee health and work ability.

The plausible mechanism linking work stress and disability pension involve both physiological (ie, allostatic load) and emotional stress reactions, which may lead to health deterioration $(16,17)$. Allostatic load increases the risk of depression, diabetes mellitus and heart disease (16), may reduce blood flow to the muscles (which may cause nerve and tissue damage) and effectiveness of the immune system (causing impaired tissue reparation) (45). Stress response is additionally linked to various systemic risk factors, such as increased sterile inflammation, hyper-coagulation and cardiac arrhythmias, which can precipitate a serious vascular or cerebral event in vulnerable individuals $(16,17)$. Moreover, indirect effects of stress - like increased health risk behaviors (such as unhealthy diet, obesity, smoking, and sedentary lifestyle) $(16,33)$ - may worsen the symptoms of musculoskeletal diseases or limit an employee's ability to recover from psychosocial and biomechanical workloads. Given that associations of different stressors with these multiple underlying mechanisms may slightly vary and the effects may accumulate, we hypothesized that multiple work stressors would be more harmful as risk factors for work disability than single stressors. There are various theoretical models to illustrate the effects of work stress. For example Lazarus et al (46) highlight the cognitive assessment of the stressful situation by the individual concerned. If the situation is perceived harmful, the possible coping strategies are then evaluated. Stress evolves individually in the course of time depending on the stressful situation, individual perceptions of it, and available coping strategies (46). Thus, it may be hypothesized that multiple stressors may have more harmful effects on employee health and work ability than single stressors because multiple stressors are likely to be perceived more stressful than a single ones. In this study, the observed prevalence of single stressors was smaller than expected suggesting that single stressors might not be perceived as harmful (or they may be more easily coped with) and thus less likely to be reported than multiple stressors. Lazarus 
and colleagues' theory also points out the shortcomings of aggregated measures to assess work stress due to ignored true differences in perceived stress between individuals.

\section{Limitations and strengths}

There are some limitations to consider with this study. Even though we controlled for numerous baseline covariates, there is still a possibility of unmeasured confounding. Second, the response rate for study survey (71\%) was reasonable. However, non-response may still have biased our results with self-assessed exposure, if stressed employees were more likely to respond than the non-stressed. Moreover, intra-class correlation coefficient (ICC) was low for aggregated ERI increasing possible misclassification bias and decreasing the ability to detect associations with study endpoints. Because ERI is a measure of individual expectations in terms of perceived fairness in gains received as compared to efforts made, it captures individual differences in addition to characteristics of the job and the work unit. A recently developed job exposure matrix for the assessment of psychosocial factors at work showed a good accuracy for job control and job strain, while its performance for other exposures was relatively low (47).

Strengths of this study include its prospective design and large study cohort, controlling for numerous confounding factors and supporting results with selfassessed and aggregated exposure. Moreover, the large cohort size enabled studying of risks related to various clusters of stressors. Furthermore, we used a reliable national pension register to assess the study endpoint (disability pension). In Finland, disability pension may be granted after approximately one year of sickness absence. Decisions are made based on a physicianwritten certificate with diagnosis according to ICD-10 and information on the treatment and rehabilitation received for the illness. The pension registers cover the entire Finnish population, which ensures practically no loss to follow-up.

\section{Concluding remarks}

We found that work stressors tend to cluster in the same individuals. The highest risk of disability pension was observed among those with strain+ERI, ERI+injustice or strain+ERI+injustice combinations, not among individuals with single stressors. In relation to disability pension due to depressive disorders, the combination of job strain+ERI+injustice and the combination of ERI+injustice were significant risk factors. In relation to disability pension due to musculoskeletal disorders, a significant risk factor was found to be the combination of strain+ERI. The results of this study show that instead of single stressors, it is important to study the clusters of work stressors, and that harmful combinations may vary depending on the health outcomes. These findings support the notion that improvement of work-related psychosocial factors may contribute to extensions to working life. To the best of our knowledge, no previous study has examined associations of multiple work stressors on disability pension or used more than one diagnosis-specific outcome.

\section{Acknowledgements}

The Academy of Finland (\#264944, \#265977 and \#267727) and the participating organizations supported this study. The Finnish Medical Foundation and the Finnish Work Environment Fund supported AJ. The Academy of Finland (\#258598, \#265174 and \#292824) supported MV. NordForsk supported MK. The authors declare no conflicts of interests.

\section{References}

1. Karasek R, Theorell T. Healthy Work: Stress, Productivity, and The Reconstruction Of Working Life. New York, NY: Basic Books. 1990.

2. Siegrist J. Adverse health effects of high-effort/low-reward conditions. J Occup Health Psychol 1996 Jan;1(1):27-41. http://dx.doi.org/10.1037/1076-8998.1.1.27.

3. Greenberg J, Colquitt JA. Handbook of Organizational Justice. New York: Lawrence Erlbaum Associates 2005.

4. Theorell T, Hammarström A, Aronsson G, Träskman Bendz L, Grape T, Hogstedt C et al. A systematic review including meta-analysis of work environment and depressive symptoms. BMC Public Health 2015 Aug;15(1):738. http:// dx.doi.org/10.1186/s12889-015-1954-4.

5. Kivimäki M, Nyberg ST, Batty GD, Fransson EI, Heikkilä $\mathrm{K}$, Alfredsson L, et al. Job strain as a risk factor for coronary heart disease: a collaborative meta-analysis of individual participant data. Lancet. 2012; 27;380(9852):1491-7.

6. Bernal D, Campos-Serna J, Tobias A, Vargas-Prada S, Benavides FG, Serra C. Work-related psychosocial risk factors and musculoskeletal disorders in hospital nurses and nursing aides: a systematic review and meta-analysis. Int J Nurs Stud 2015 Feb;52(2):635-48. http://dx.doi. org/10.1016/j.ijnurstu.2014.11.003.

7. Koch P, Schablon A, Latza U, Nienhaus A. Musculoskeletal pain and effort-reward imbalance--a systematic review. BMC Public Health 2014 Jan;14:37. http://dx.doi. org/10.1186/1471-2458-14-37.

8. Madsen IE, Nyberg ST, Magnusson Hanson LL, Ferrie JE, Ahola K, Alfredsson L et al.; IPD-Work Consortium. Job 
strain as a risk factor for clinical depression: systematic review and meta-analysis with additional individual participant data. Psychol Med 2017 Jun;47(8):1342-56. http://dx.doi.org/10.1017/S003329171600355X.

9. Nyberg ST, Fransson EI, Heikkilä K, Ahola K, Alfredsson L, Bjorner JB et al.; IPD-Work Consortium. Job strain as a risk factor for type 2 diabetes: a pooled analysis of 124,808 men and women. Diabetes Care 2014 Aug;37(8):2268-75. http://dx.doi.org/10.2337/dc13-2936.

10. Juvani A, Oksanen T, Salo P, Virtanen M, Kivimäki M, Pentti $\mathrm{J}$ et al. Effort-reward imbalance as a risk factor for disability pension: the Finnish Public Sector Study. Scand J Work Environ Health 2014 May;40(3):266-77. http://dx.doi. org/10.5271/sjweh.3402.

11. Mäntyniemi A, Oksanen T, Salo P, Virtanen M, Sjösten N, Pentti J et al. Job strain and the risk of disability pension due to musculoskeletal disorders, depression or coronary heart disease: a prospective cohort study of 69,842 employees. Occup Environ Med 2012 Aug;69(8):574-81. http://dx.doi. org/10.1136/oemed-2011-100411.

12. Canivet C, Choi B, Karasek R, Moghaddassi M, StalandNyman C, Östergren PO. Can high psychological job demands, low decision latitude, and high job strain predict disability pensions? A 12-year follow-up of middle-aged Swedish workers. Int Arch Occup Environ Health 2013 Apr;86(3):307-19. http://dx.doi.org/10.1007/s00420-0120766-4.

13. Stattin M, Järvholm B. Occupation, work environment, and disability pension: a prospective study of construction workers. Scand J Public Health 2005;33(2):84-90. http:// dx.doi.org/10.1080/14034940410019208.

14. Juvani A, Oksanen T, Virtanen M, Elovainio M, Salo P, Pentti J et al. Organizational justice and disability pension from all-causes, depression and musculoskeletal diseases: A Finnish cohort study of public sector employees. Scand J Work Environ Health 2016 Sep;42(5):395-404. http:// dx.doi.org/10.5271/.3582.

15. Knardahl S, Johannessen HA, Sterud T, Härmä M, Rugulies $\mathrm{R}$, Seitsamo J et al. The contribution from psychological, social, and organizational work factors to risk of disability retirement: a systematic review with meta-analyses. BMC Public Health 2017 Feb;17(1):176. http://dx.doi. org/10.1186/s12889-017-4059-4.

16. McEwen BS. Protective and damaging effects of stress mediators. N Engl J Med 1998 Jan;338(3):171-9. http:// dx.doi.org/10.1056/NEJM199801153380307

17. Kivimäki M, Steptoe A. Effects of stress on the development and progression of cardiovascular disease. Nat Rev Cardiol 2018 Apr;15(4):215-29. http://dx.doi.org/10.1038/ nrcardio.2017.189.

18. Dragano N, Siegrist J, Nyberg ST, Lunau T, Fransson EI, Alfredsson L et al.; IPD-Work consortium. Effortreward imbalance at work in relation to incident coronary heart disease: a multicohort study of 90,164 individuals. Epidemiology 2017 Jul;28(4):619-26. http://dx.doi. org/10.1097/EDE.0000000000000666.
19. OECD. Sickness, Disability and Work: Breaking the Barriers. A Synthesis of Findings across OECD Countries. Paris: OECD Publishing; 2010.

20. Woolf AD, Pfleger B. Burden of major musculoskeletal conditions. Bull World Health Organ 2003;81(9):646-56.

21. Kolstad HA, Hansen AM, Kærgaard A, Thomsen JF, Kaerlev L, Mikkelsen S et al. Job strain and the risk of depression: is reporting biased? Am J Epidemiol 2011 Jan;173(1):94-102. http://dx.doi.org/10.1093/aje/kwq318.

22. Courvoisier DS, Perneger TV. Validation of alternative formulations of job strain. J Occup Health 2010;52(1):5-13. http://dx.doi.org/10.1539/joh.L9084.

23. Stansfeld SA, Shipley MJ, Head J, Fuhrer R. Repeated job strain and the risk of depression: longitudinal analyses from the Whitehall II study. Am J Public Health 2012 Dec;102(12):2360-6. http://dx.doi.org/10.2105/ AJPH.2011.300589.

24. Siegrist J, Starke D, Chandola T, Godin I, Marmot M, Niedhammer I et al. The measurement of effort-reward imbalance at work: european comparisons. Soc Sci Med 2004 Apr;58(8):1483-99. http://dx.doi.org/10.1016/S02779536(03)00351-4.

25. Moorman R. Relationship between organizational justice and organizational citizenship behaviours: do fairness perception influence employee citizenship? J Appl Psychol 1991;76(6):845-55. http://dx.doi.org/10.1037/00219010.76 .6 .845

26. Kouvonen A, Kivimäki M, Elovainio M, Väänänen A, De Vogli R, Heponiemi T et al. Low organisational justice and heavy drinking: a prospective cohort study. Occup Environ Med 2008 Jan;65(1):44-50. http://dx.doi.org/10.1136/ oem.2007.032755.

27. Statistics Finland. Classification of Occupations. Helsinki: Statistics Finland; 1987.

28. Kela (2016). Decision on reimbursement entitlement and new Kela card. Special rate of reimbursement. Available from: http://www.kela.fi/web/en/medicine-expenses-specialreimbursement.

29. Kouvonen A, Kivimäki M, Elovainio M, Pentti J, Linna A, Virtanen $M$ et al. Effort/reward imbalance and sedentary lifestyle: an observational study in a large occupational cohort. Occup Environ Med 2006 Jun;63(6):422-7. http:// dx.doi.org/10.1136/oem.2005.020974.

30. Schuit AJ, van Loon AJ, Tijhuis M, Ocké M. Clustering of lifestyle risk factors in a general adult population. Prev Med 2002 Sep;35(3):219-24. http://dx.doi.org/10.1006/ pmed.2002.1064.

31. Hintsanen M, Hintsa T, Widell A, Kivimäki M, Raitakari OT, Keltkangas-Järvinen L. Negative emotionality, activity, and sociability temperaments predicting long-term job strain and effort-reward imbalance: a 15-year prospective followup study. J Psychosom Res 2011 Aug;71(2):90-6. http:// dx.doi.org/10.1016/j.jpsychores.2011.02.012.

32. Arial M, Wild P. Effort, reward and self-reported mental health: a simulation study on negative affectivity bias. 
BMC Med Res Methodol 2011 Aug;11:121. http://dx.doi org/10.1186/1471-2288-11-121.

33. Kasl SV. Measuring job stressors and studying the health impact of the work environment: an epidemiologic commentary. J Occup Health Psychol 1998 Oct;3(4):390 401. http://dx.doi.org/10.1037/1076-8998.3.4.390.

34. Herr RM, Bosch JA, Loerbroks A, van Vianen AE, Jarczok $\mathrm{MN}$, Fischer JE et al. Three job stress models and their relationship with musculoskeletal pain in blue- and whitecollar workers. J Psychosom Res 2015 Nov;79(5):340-7. http://dx.doi.org/10.1016/j.jpsychores.2015.08.001.

35. de Jonge J, Bosma H, Peter R, Siegrist J. Job strain, effortreward imbalance and employee well-being: a large-scale cross-sectional study. Soc Sci Med 2000 May;50(9):131727. http://dx.doi.org/10.1016/S0277-9536(99)00388-3.

36. Kivimäki M, Vahtera J, Elovainio M, Virtanen M, Siegrist J. Effort-reward imbalance, procedural injustice and relational injustice as psychosocial predictors of health: complementary or redundant models? Occup Environ Med 2007 Oct;64(10):659-65. http://dx.doi.org/10.1136/ oem.2006.031310.

37. Head J, Kivimäki M, Siegrist J, Ferrie JE, Vahtera J, Shipley $\mathrm{MJ}$ et al. Effort-reward imbalance and relational injustice at work predict sickness absence: the Whitehall II study. J Psychosom Res 2007 Oct;63(4):433-40. http://dx.doi. org/10.1016/j.jpsychores.2007.06.021.

38. Ndjaboué R, Brisson C, Vézina M. Organisational justice and mental health: a systematic review of prospective studies. Occup Environ Med 2012 Oct;69(10):694-700. http://dx.doi.org/10.1136/oemed-2011-100595.

39. Ota A, Masue T, Yasuda N, Tsutsumi A, Mino Y, Ohara H. Association between psychosocial job characteristics and insomnia: an investigation using two relevant job stress models--the demand-control-support (DCS) model and the effort-reward imbalance (ERI) model. Sleep Med 2005 Jul;6(4):353-8. http://dx.doi.org/10.1016/j. sleep.2004.12.008.

40. Trudel X, Brisson C, Milot A, Masse B, Vézina M. Psychosocial work environment and ambulatory blood pressure: independent and combined effect of demandcontrol and effort-reward imbalance models. Occup Environ Med 2013 Nov;70(11):815-22. http://dx.doi.org/10.1136/ oemed-2013-101416.
41. Bosma H, Peter R, Siegrist J, Marmot M. Two alternative job stress models and the risk of coronary heart disease. Am J Public Health 1998 Jan;88(1):68-74. http://dx.doi. org/10.2105/AJPH.88.1.68.

42. Rydstedt LW, Devereux J, Sverke M. Comparing and combining the demand-control- support model and the effort reward imbalance model to predict long-term mental strain. Eur J Work Organ Psychol 2007;16(3):261-78. http://dx.doi. org/10.1080/13594320601182311.

43. Peter R, Siegrist J, Hallqvist J, Reuterwall C, Theorell T; SHEEP Study Group. Psychosocial work environment and myocardial infarction: improving risk estimation by combining two complementary job stress models in the SHEEP Study. J Epidemiol Community Health 2002 Apr;56(4):294-300. http://dx.doi.org/10.1136/jech.56.4.294.

44. Calnan M, Wainwright D, Almond S. Job Strain, Effort-Reward Imbalance and Mental Distress: A study of occupations in general medical practice. Work Stress 2000;14(4):297-311. http://dx.doi.org/10.1080/02678370110040920.

45. Carayon P, Smith MJ, Haims MC. Work organization, job stress, and work-related musculoskeletal disorders. Hum Factors 1999 Dec;41(4):644-63. http://dx.doi. org/10.1518/001872099779656743.

46. Kinnunen U, Feldt T, Mauno S, editors. Työ leipälajina. Työhyvinvoinnin psykologiset perusteet [Work; a cup of tea. Basics of workplace wellbeing]. Juva (Finland): PSkustannus, 2008 (pp17, 24-25).

47. Solovieva S, Pensola T, Kausto J, Shiri R, Heliövaara M, Burdorf A, et al. Evaluation of the validity of job exposure matrix for psychosocial factors at work. PLoS One. 2014;30;9(9):e108987.

Received for publication: 20 November 2017 